\section{Qualitative and Quantitative Estimation of Water Insoluble Drugs from its Formulations Simultaneously: a Hydrotropic Approach}

${ }^{*}$ Rajesh Sharma, Geetam Pathodiya and Ganesh Prasad Mishra
*Corresponding Author

Dr. Rajesh Sharma

Head, School of Pharmacy

Devi Ahilya Vishwa Vidyalaya

Takshashila Campus, Khandwa Road Indore, Madhya Pradesh India - 452017

School of Pharmacy, Devi Ahilya Vishwa Vidyalaya, Takshashila Campus, Khandwa Road, Indore, Madhya Pradesh, India - 452017.

Received - 09 September 2010

Accepted for Publication - 31 October 2010

\begin{abstract}
Three accurate, precise, sensitive and economical procedures for simultaneous determination of ciprofloxacin hydrochloride and tinidazole in tablet dosage form have been developed. In the present investigation, 1.0M urea solution (hydrotropic solubilising agent) was employed to solubilise, ciprofloxacin, a poorly water-soluble drug, from fine powder of its tablets to carryout spectrophotometric analysis. The methods employed were derivative spectrophotometry method, area under curve method and multi-component method. The result showed that Beer,s-Lambert,s law was obeyed in concentration range of $5-50 \mu \mathrm{g} / \mathrm{ml}$ with good linearity, with a $R^{2}$ value $>0.99$, for both the drugs in all the methods. The recoveries were within $99.42-101.27 \%$ for ciprofloxacin hydrochloride and $99.61-101.81 \%$ for tinidazole. Precision was good with acceptable limits of detection (LOD) and quantitation (LOQ) for both compounds. The optimized methods showed good reproducibility and recovery with standard deviation of $<1.0 \%$ and percent relative standard deviation less then $2.0 \%$.
\end{abstract}

Key Words: Derivative spectrophotometry method, area under curve method, multi-component method, ciprofloxacin hydrochloride, tinidazole, hydrotropic agent.

\title{
INTRODUCTION
}

Hydrotropy is solubilising effect in water caused by materials that need not be surface active and that do not need to form micelles to effect their action. Hydrotropes are short chain organic compounds with polar groups that could serve as agents to dissolve poorly water soluble substances into water, if added in high concentrations (Swarbrick 2007; Coffman et al., 1996). Hydrotropy is used for solubility enhancement of different class of drugs such as anti-tumor, anti-viral, anti-inflammatory, antipyretic and analgesic drugs, xanthine derivatives etc. Hydrotropy is successfully applied for solubility enhancement of nimueslide, riboflavin, nifedipine, xanthine derivatives like theophylline and caffeine (Lee et al., 2005; Truelove et al., 1987; Jain et al., 1998; Etman et al., 1999). Various organic solvents have been employed for the solubilisation of poorly water soluble drugs for spectrophotometric estimations but due to some drawbacks of organic solvents such as higher cost, toxicity, pollution and error in analysis due to volatile nature of solvents, this approach can be conveniently applied to wide range of water insoluble compounds and thus the use of organic solvents can be precluded. Chemically ciprofloxacin hydrochloride $(\mathrm{CPH})$ is 1-cyclopropyl-6-fluoro-1, 4-dihydro-4-oxo-7-(1-piperazinyl)-3-quinolinecarboxylic acid which is a flouroquinolone derivative and antimicrobial agent with potent activity against a broad spectrum of bacteria (Indian Pharmacopoeia, 1996; British Pharmacopoeia, 1998; United State Pharmacopoeia, 2002). Literature review revealed that chromatographic method was reported for its estimation from tablet formulation (Garcia and Albero, 2001). Chemically tinidazole (TZ) is 1-(2ethylsulfonylethyl)-2-methyl-5-nitro-imidazole which is an antiprotozoal and anti-bacterial drug (Current Index of Medical Specialities, 2006). These drugs are being used either alone or in combination for the treatment of diarrhoea and dysentery of amoebic, bacterial or mixed origin (Salomies and Salo, 2005). Literature review revealed that chromatographic method was reported for its estimation from tablet dosage form. Since no spectrophotometric methods have been reported for simultaneous estimation of $\mathrm{CPH}$ and $\mathrm{TZ}$ in combined dosage forms, an attempt has been made to develop simple, sensitive, economical, rapid, precise and accurate methods to analyze the drugs simultaneously. 


\section{MATERIALS AND METHODS}

\section{Instrumentation}

UV-Visible double beam spectrophotometer, Shimadzu model-1700 having spectral bandwidth $3 \mathrm{~nm}$ and of wavelength accuracy $\pm 1 \mathrm{~nm}$, with $1 \mathrm{~cm}$ quartz cells was used. All weighing were done on electronic balance (Shimadzu, model AY - 120).

\section{Reagents and chemicals}

Analytically pure samples of $\mathrm{CPH}$ and $\mathrm{TZ}$ were obtained as gift samples from Zest Pharma Pvt. Ltd, Indore (MP), India and were used as such without further purification. The tablet dosage form, Cipract TZ (containing CPH 500mg with TZ $600 \mathrm{mg}$ ) was procured from the local market, Indore, India. 1.0 M urea was selected as hydrotropic solubilising agent. All other materials used were of analytical reagent grade.

\section{Derivative spectrophotometry method (A)}

In this method (Abdel-Aziz et al., 2002) $20 \mu \mathrm{gmL}^{-1}$ solution for both the drugs was prepared and scanned in the range of $400 \mathrm{~nm}$ to $200 \mathrm{~nm} .272 \mathrm{~nm}$ and $321 \mathrm{~nm}$ were selected as analytical wavelengths for estimation of $\mathrm{CPH}$ and TZ respectively as $\mathrm{CPH}$ had zero crossing point at $272 \mathrm{~nm}$ while TZ had zero crossing point at $321 \mathrm{~nm}$ (Figure 1). Calibration curves were plotted for $\mathrm{CPH}$ (5$\left.50 \mathrm{\mu gmL}^{-1}\right)$ at $272 \mathrm{~nm}$ and $\mathrm{TZ}\left(5-45 \mu \mathrm{gmL}^{-1}\right)$ at $321 \mathrm{~nm}$ taking $\mathrm{dA} / \mathrm{d} \lambda$ vs concentration. The concentrations of both the drugs were obtained from the standard calibration curves by interpolation method.

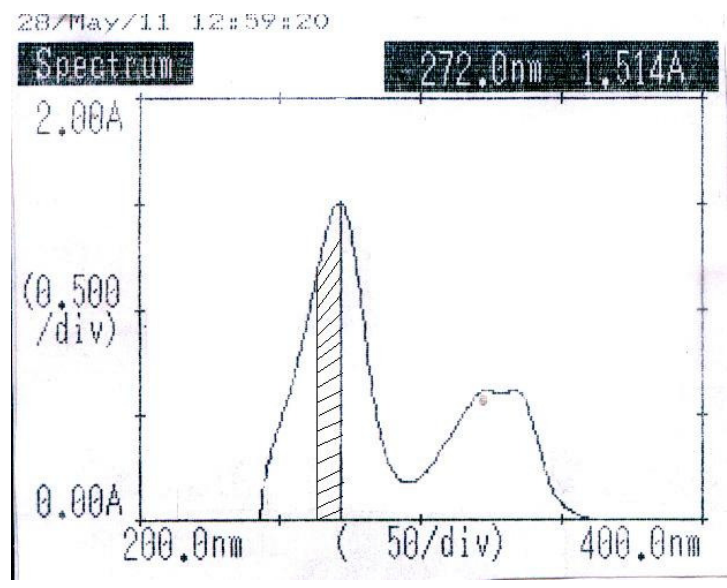

Figure 1: First order derivative overlain spectra of $\mathrm{CPH}$ and TZ.

\section{Area under curve method (B)}

This method (Zahran et al., 2007) involved the calculation of integrated value of absorbance with respect to wavelength. Area calculation processing item calculates the area of bounded by the curve and horizontal axis. Here horizontal axis represents baseline.

$$
(\alpha+\beta)=\int_{\lambda_{2}}^{\lambda_{1}} A d \lambda
$$

Where, $\alpha=$ area of portion bounded by curve data and a straight line connecting the start and end point, $\beta=$ area of portion bounded by a straight line connecting the start and end point on curve data and horizontal axis, $\lambda_{1}$ and $\lambda_{2}$ are wavelengths representing start and end point of curve region.

This method involved calculation of concentration for $\mathrm{CPH}$ in the regions of $272-270 \mathrm{~nm}$ and for TZ in the region of $320-317 \mathrm{~nm}$, these regions were selected on the basis of repeated observation that plot area calculation of pure sample drug against the concentration. The UV spectra of $\mathrm{CPH}$ and $\mathrm{TZ}$ along with its area under curve region were reported in (Figure $2 \mathrm{~A}$ and $2 \mathrm{~B}$ ) respectively.

$$
\int_{270}^{272} A d \lambda=K_{1} C_{1} \ldots . .\left(\text { Eqn.1) } \quad \int_{317}^{320} A d \lambda=K_{2} C_{2} \ldots . .(\text { Eqn.2) }\right.
$$




$$
\int_{270}^{272} A d \lambda=K_{3} C_{1} \ldots \text { (Eqn.3) } \quad \int_{317}^{320} A d \lambda=K_{4} C_{2} \ldots . \text { (Eqn.4) }
$$

Where $\mathrm{C}_{1}$ and $\mathrm{C}_{2}$ were concentration of $\mathrm{CPH}$ and $\mathrm{TZ}$ respectively in $\mu \mathrm{g} / \mathrm{ml}$ and $\mathrm{K}_{1}, \mathrm{~K} 2, \mathrm{~K} 3$ and $\mathrm{K}_{4}$ were constant having values $0.2371,0.4802,0.2013$ and 0.1008 respectively. Area of curve between 272-270 nm and 320-317 nm represented as $\int_{270}^{272} A d \lambda$ and $\int_{317}^{320} A d \lambda$ for $\mathrm{CPH}$ and TZ respectively. In view of that, following two final equations were developed for estimation of $\mathrm{CPH}$ and TZ.

$$
\int_{270}^{272} A d \lambda=K_{1} C_{1}+K_{2} C_{2} \ldots . \text { (Eqn.5) } \quad \int_{317}^{320} A d \lambda=K_{3} C_{1}+K_{4} C_{2} \ldots . . \text { (Eqn.6) }
$$

Sample solutions were scanned and area was calculated within the indicated wavelength regions. Concentrations of both components were calculated using Eqn. $5 \& 6$.
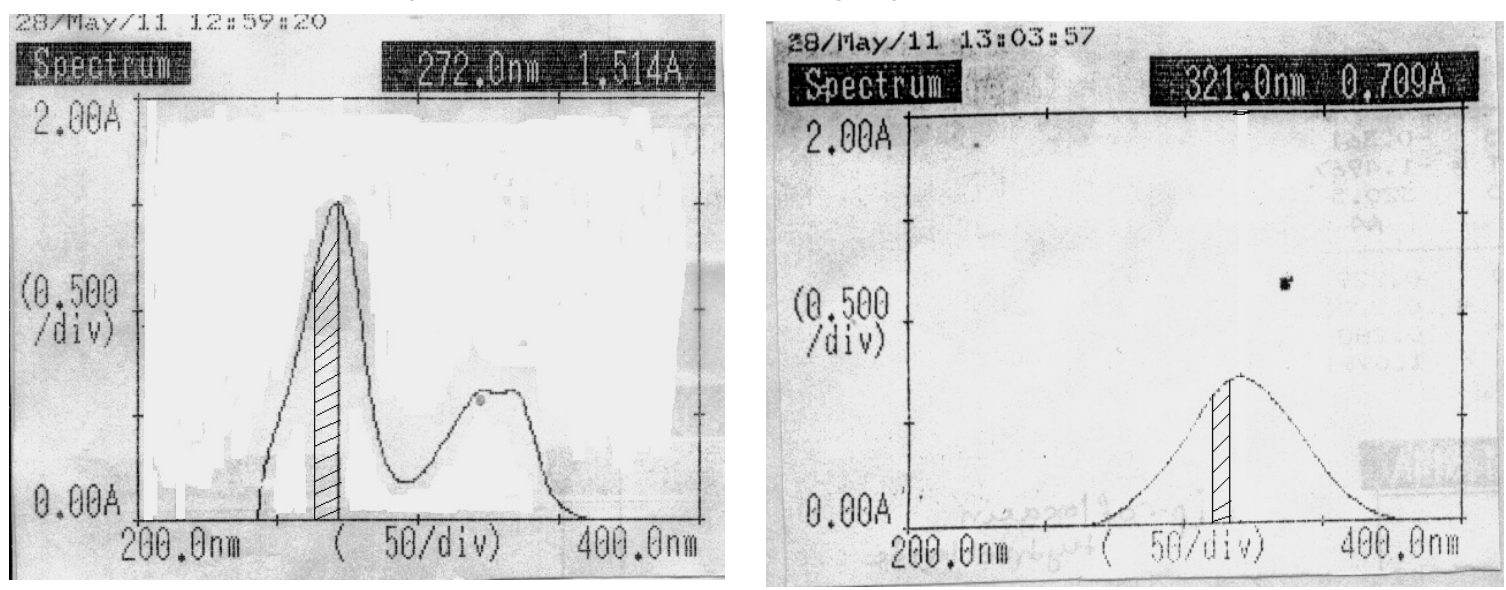

Figure 2: Left (A) UV spectra of CPH along with area under curve and right (B) UV spectra of TZ along with area under curve

\section{Multi-component method (C)}

In this method (Zahran et al., 2007) six mixed standards of CPH and TZ in the ratio of 5:6 having concentrations in $\mu \mathrm{g} / \mathrm{ml}$ of $5: 6,10: 12,15: 18,20: 24,25: 30$ and 30:36 were prepared by appropriate dilution of the standard stock solutions and scanned in the region of $400 \mathrm{~nm}$ to $200 \mathrm{~nm}$. Sampling wavelengths (272 $\mathrm{nm}$ and $321 \mathrm{~nm}$ ) were selected on trial and error basis. The concentration of individual drug was fed to the multi-component mode of the instrument. The instrument was collected and was compiled the spectral data from mixed standards and concentration of each component were obtained by spectral data of sample solution with reference to that of six mixed standards. Overlain spectra of mixed standards are given in Figure 3.

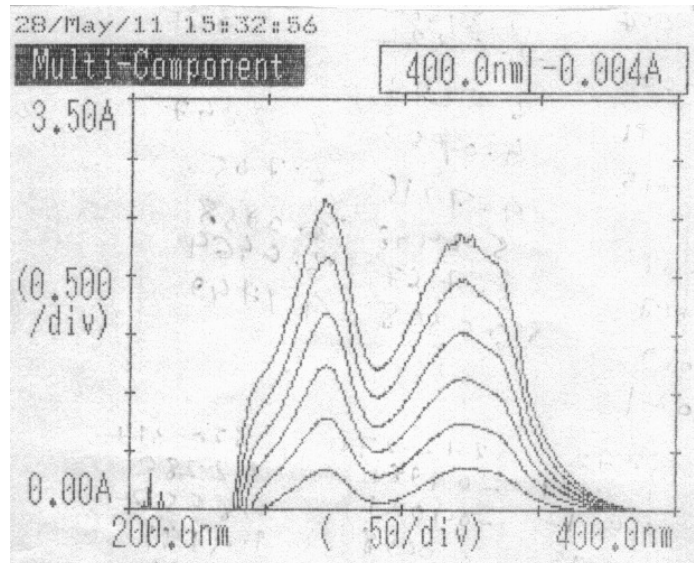

Figure 3: Overlain spectra of mixed standards of CPH and TZ. 


\section{Preliminary solubility studies of drugs}

Solubility of both drugs was determined at $28 \pm 2^{0} \mathrm{C}$. An excess amount of drug was added to two screw capped $30 \mathrm{ml}$ glass vials containing different aqueous systems viz distilled water, buffer at $\mathrm{pH} 6.4$, buffer at $\mathrm{pH} 8.2$, and $1.0 \mathrm{M}$ urea. The vials were shaken mechanically for $12 \mathrm{hrs}$. at $28 \pm$ $1^{\circ} \mathrm{C}$ in a mechanical shaker. These solutions were allowed to equilibrate for next $24 \mathrm{hrs}$. and then centrifuged for 5 mins. at $2000 \mathrm{rpm}$. The supernatant liquid was taken for appropriate dilution after filtering through Whitman filter paper \#41 and analyzed spectrophotometrically against corresponding solvent blank. After analysis, it was found that the enhancement in the solubility of $\mathrm{CPH}$ and TZ was found to be more than 30 and 10 folds respectively in $1.0 \mathrm{M}$ urea as compared to solubility studies in other solvents.

\section{Preparation of standard stock solution and calibration curves of $\mathrm{CPH}$ and TZ}

About $50 \mathrm{mg}$ each of CPZ and TZ were accurately weighed and transferred to $50 \mathrm{ml}$ of volumetric flask separately. $40 \mathrm{ml}, 1.0 \mathrm{M}$ urea was used to solubilise after shaking for 10 to 15 minutes. Rest of the volume was made up with distilled water to get solution of $1000 \mathrm{mgmL}^{-1}$. Stock solutions of $100 \mathrm{gm} \mathrm{L}^{-1}$ of each drugs were prepared by further dilution and scanned over the range of $400 \mathrm{~nm}$ - $200 \mathrm{~nm}$ in the spectrum mode to get the overlain spectra of both drugs. The spectra exhibited pick absorbance at $272 \mathrm{~nm}$ and $321 \mathrm{~nm}$ for $\mathrm{CPH}$ and TZ respectively. Beer's-Lambert's law obeyed in the range of 5-50 $\mathrm{ggmL}^{-1}$ and $5-45 \mu \mathrm{gmL}^{-1}$ for $\mathrm{CPH}$ and TZ respectively. Six mixed standards $5 \mathrm{ml}, 10 \mathrm{ml}, 15 \mathrm{ml}, 20 \mathrm{ml}, 25 \mathrm{ml}, 30 \mathrm{ml}$ for both $\mathrm{CPH}$ and TZ were prepared from stock solutions of $\mathrm{CPH}$ and $\mathrm{TZ}$ for further study.

\section{Analysis of tablet formulation}

Twenty tablets of TZ were taken and their average weight was determined, they were crushed to fine powder. Then powder equivalent to $50 \mathrm{mg}(101.91 \mathrm{mg})$ of TZ was taken in $50 \mathrm{ml}$ volumetric flask and $40 \mathrm{ml}, 1.0 \mathrm{M}$ urea was used to solubilise after shaking for 10 to 15 minutes. Rest of the volume was made up with distilled water to get solution of $1000 \mu \mathrm{gmL}^{-1}$. Stock solutions of $100 \mu \mathrm{g}$ $\mathrm{mL}^{-1}$ of each drugs were prepared by further dilution. The supernatant liquid was transferred to 50 $\mathrm{ml}$ of volumetric flask through a Whitman filter paper \#41. The residue was washed twice with water and the combined filtrate was made up to $50 \mathrm{ml}$ mark with water. The above solution was further diluted to get a solution containing $12 \mu \mathrm{gmL}^{-1}$ of TZ. Similarly dilution for CPZ was made containing $10 \mathrm{\mu gmL}^{-1}$ of $\mathrm{CPH}$. The above binary mixture was analyzed at appropriate wavelengths and values of the absorbance were substituted in the respective formulas (Eqn.1, 2, 3, 4) to obtain the content of $\mathrm{CPH}$ and TZ. CPH and TZ were determined from their calibration curve plotted between absorbance difference and concentration.

The recovery studies, Validation of the developed methods as per ICH guidelines (International Conference on Harmonization, 1995), accuracy, precision, repeatability, limit of detection (LOD) and limit of quantitation (LOQ), intermediate precision (inter-day and intra-day precision) were studied for the data obtained.

\section{RESULTS AND DISCUSSION}

Table 1: Result of pharmaceutical formulation analysis

\begin{tabular}{|c|c|c|c|c|c|c|}
\hline \multirow{2}{*}{ Parameters } & \multicolumn{2}{|c|}{ Method A } & \multicolumn{2}{|c|}{ Method B } & \multicolumn{2}{|c|}{ Method C } \\
\hline & $\mathrm{CPH}$ & TZ & $\mathrm{CPH}$ & TZ & $\mathrm{CPH}$ & TZ \\
\hline Label claim (mg/Tab) & 500 & 600 & 500 & 600 & 500 & 600 \\
\hline Found (mg/Tab) & 499.87 & 600.09 & 500.43 & 601.24 & 501.56 & 600.11 \\
\hline Drug content $^{\mathrm{a}}$ & 100.03 & 100.82 & 99.55 & 101.05 & 99.70 & 100.31 \\
\hline \pm S.D & 0.384 & 0.530 & 0.120 & 0.764 & 0.281 & 0.296 \\
\hline$\%$ COV & 0.331 & 0.284 & 0.421 & 0.108 & 0.529 & 0.111 \\
\hline SE & 0.403 & 0.203 & 0.681 & 0.303 & 0.298 & 0.550 \\
\hline
\end{tabular}

${ }^{a}$ Value for drug content (\%) are the mean of six estimation, Method A: Derivative spectrophotometry method, Method B: Area under curve method, Method C: Multi-component method S.D: Standard Deviation, COV : Coefficient of Variance and S.E : Standard Error. 
Table 2: Result of recovery studies

\begin{tabular}{|c|c|c|c|c|c|c|}
\hline \multirow{2}{*}{ Method } & \multirow{2}{*}{ Drug } & \multirow{2}{*}{$\begin{array}{c}\text { Lebel } \\
\text { claim } \\
\text { (Mg/tab) }\end{array}$} & \multicolumn{2}{|c|}{ Amount (mg/ml) } & \multirow{2}{*}{ \%Recovery \pm S.D. } & \multirow{2}{*}{ cov\% } \\
\hline & & & Taken & Added & & \\
\hline \multirow{7}{*}{ Method A } & \multirow{3}{*}{$\mathrm{CPH}$} & \multirow{3}{*}{500} & 30 & 5 & $99.42 \pm 0.442$ & 0.321 \\
\hline & & & 60 & 10 & $101.18 \pm 0.820$ & 0.521 \\
\hline & & & 90 & 15 & $99.93 \pm 0.001$ & 0.119 \\
\hline & & & & & & \\
\hline & \multirow{3}{*}{$\mathrm{TZ}$} & \multirow{3}{*}{600} & 30 & 5 & $101.81 \pm 0.420$ & 0.219 \\
\hline & & & 60 & 10 & $99.95 \pm 0.103$ & 0.104 \\
\hline & & & 90 & 15 & $100.27 \pm 0.711$ & 0.471 \\
\hline \multirow{7}{*}{ Method B } & \multirow{3}{*}{$\mathrm{CPH}$} & \multirow{3}{*}{500} & 30 & 5 & $100.01 \pm 0.182$ & 0.413 \\
\hline & & & 60 & 10 & $101.18 \pm 0.307$ & 0.108 \\
\hline & & & 90 & 15 & $99.99 \pm 0.182$ & 0.222 \\
\hline & & & & & & \\
\hline & \multirow{3}{*}{$\mathrm{TZ}$} & \multirow{3}{*}{600} & 30 & 5 & $100.26 \pm 0.326$ & 0.209 \\
\hline & & & 60 & 10 & $101.32 \pm 0.621$ & 0.491 \\
\hline & & & 90 & 15 & $99.61 \pm 0.536$ & 0.203 \\
\hline \multirow{7}{*}{ Method C } & \multirow{4}{*}{$\mathrm{CPH}$} & \multirow{3}{*}{500} & 30 & 5 & $100.21 \pm 0.110$ & 0.720 \\
\hline & & & 60 & 10 & $99.92 \pm 0.320$ & 0.331 \\
\hline & & & 90 & 15 & $101.27 \pm 0.296$ & 0.228 \\
\hline & & & & & & \\
\hline & \multirow{3}{*}{$\mathrm{TZ}$} & \multirow{3}{*}{600} & 30 & 5 & $101.31 \pm 0.200$ & 0.120 \\
\hline & & & 60 & 10 & $100.01 \pm 0.142$ & 0.311 \\
\hline & & & 90 & 15 & $101.58 \pm 0.216$ & 0.295 \\
\hline
\end{tabular}

$\%$ Recovery is mean of three estimations, Method A: Derivative spectrophotometry Method, Method B: Area under curve method, Method C: Multi-component method, S.D is Standard Deviation and COV is Coefficient of Variance.

Table 3: Intraday, Interdays, LOD and LOQ data of tablet formulation.

\begin{tabular}{|c|c|c|c|c|c|c|c|}
\hline \multirow{2}{*}{ Method } & \multirow{2}{*}{ Drug } & \multirow{2}{*}{$\begin{array}{l}\text { Intraday recision } \\
\% \operatorname{COV}(\mathbf{n}=3)\end{array}$} & \multicolumn{3}{|c|}{ Interday precision \%COV } & \multirow{2}{*}{$\begin{array}{l}\text { LOD } \\
(\mu \mathrm{g} / \mathrm{ml})\end{array}$} & \multirow{2}{*}{$\begin{array}{c}\text { LOQ } \\
(\mu \mathrm{g} / \mathrm{ml})\end{array}$} \\
\hline & & & Day $1^{a}$ & Day $2^{a}$ & Day $3^{a}$ & & \\
\hline \multirow{2}{*}{ Method A } & $\mathrm{CPH}$ & 0.331 & 0.215 & 0.300 & 0.309 & 0.127 & 0.718 \\
\hline & $\mathrm{TZ}$ & 0.282 & 0.490 & 0.118 & 0.119 & 0.180 & 0.821 \\
\hline \multirow{2}{*}{ Method B } & $\mathrm{CPH}$ & 0.167 & 0.210 & 0.337 & 0.715 & 0.101 & 1.013 \\
\hline & $\mathrm{TZ}$ & 0.329 & 0.119 & 0.213 & 0.111 & 0.212 & 0.991 \\
\hline \multirow{2}{*}{ Method C } & $\mathrm{CPH}$ & 0.510 & 0.110 & 0.329 & 0.613 & 0.180 & 1.917 \\
\hline & $\mathrm{TZ}$ & 0.122 & 0.391 & 0.110 & 0.912 & 0.441 & 2.011 \\
\hline
\end{tabular}

All the described UV spectrophotometric methods were found to be simple, accurate, economic and rapid for simultaneous estimation of $\mathrm{CPH}$ and $\mathrm{TZ}$ in tablet dosage forms. By performing these methods it was found that both drugs showed good regression value at their respective wavelengths and the average content of the compounds were 100.03 and $100.81 \%$ in method $A$, 99.55 and $101.05 \%$ in method B and 99.70 and $100.31 \%$ in method C for CPH and TZ respectively. The results were reported in Table 1. To check the accuracy of the developed methods and to study the interference of formulation additives, analytical recovery experiments was carried out by standard addition method. Total amount of drug found and percentage recovery was calculated. The recoveries were within $99.42-101.27 \%$ for CPH and $99.61-101.81 \%$ for TZ. The results were reported in Table 2. Precision was good with acceptable limits of detection (LOD) and quantitation (LOQ) for both compounds. The results were reported in Table 3 . The optimized methods showed good reproducibility and recovery with standard deviation of $<1.0 \%$ and percent relative standard deviation less then $2.0 \%$. Since urea do not interfere above $245 \mathrm{~nm}$ other poorly water-soluble drugs can also be estimated above $245 \mathrm{~nm}$ by hydrotropy avoiding the use of 
organic solvents. There was no interference of urea and commonly used additives present in tablet formulations. A critical evaluation of the proposed methods was performed by statistical analysis of the experimental data. In order to demonstrate the validity and applicability of the proposed methods, recovery studies were performed by analyzing synthetic mixture of $\mathrm{CPH}$ and TZ with different composition ratio. Hence, the proposed methods could be successfully applied to the determination of $\mathrm{CPH}$ and $\mathrm{TZ}$ in the commercially available bulk and tablet dosage forms.

\section{CONCLUSION}

It may be concluded that the proposed methods of analysis are new, simple, cost-effective, environmentally friendly, safe, accurate and reproducible. Definitely there is further scope of using $1.0 \mathrm{M}$ urea solution as solubilising agent for other poorly water-soluble drugs. There was no interference of urea in the estimation. The proposed method can be successfully employed in the routine analysis of $\mathrm{CPH}$ and $\mathrm{TZ}$ containing dosage forms.

\section{ACKNOWLEDGEMENT}

The authors express their gratitude to the Zest Pharma Pvt. Ltd, Indore (MP), India for providing gift samples of pure drug and one of the author Geetam Pathodiya is thankful to AICTE for providing financial assistance.

\section{REFERENCES}

Abdel-Aziz MW, Omayama AR, Azza AG, Hoda M, Marwa SM. (2002), Spectrophotometric determination of omeprazole, lansoprazole and pantoprazole in pharmaceutical formulation. $J$ Pharm Biomed Anal. 30(4): 1133-1142.

British Pharmacopoeia. (1998), The Stationary Office, London. 1296.

Coffman RE, Kildsig D.(1996), Hydrotropic solubilization-mechanistic studies. Pharm. Res. 13: $1460-1463$.

Current Index of Medical Specialities. (2006), Medimedia Health Private Ltd. Bangalore, 394.

Etman MA, Hada AH. (1999), Hydrotropic and cosolvent solubilization of indomethacin Acta Pharm. 49: 291-298.

Garcia MS, Albero MI. (2001), Analysis of ciprofloxacin by High Performance Liquid Chromatography. Indian J Pharm. Biopharm. 61: 87.

Indian Pharmacopoeia. (1996), Vol. 1, The Controller of Publication, New Delhi. 764.

International Conference on Harmonization. (1995), Q2A: Text on Validation of Analytical Procedures: Definitions and Terminology,US FDA Federal Register, 60.

Jain NK, Patel VV, Taneja LN. (1998), Hydrotropic solubilization of nifedipine. Pharmazie. 43:194-198.

Lee J, Lee SC, Acharya G, Chang C, Parke R. (2005), Hydrotropic solubilization of Paclitaxel. Pharm. Res. 20: 1022-1030.

Salomies H, Salo JP. (2005), An HPLC study of tinidazole. Chromagraphia. 36:79.

Swarbrick J. (2007), Encyclopedia of Pharmaceutical Technology, $3^{\text {rd }}$ ed. pp. 2919. Marcel Dekker, (NY).

Truelove J, Bawarshi-Massac R, Chen NR, Hussain A. (1987), Solubility enhancement of some developmental anti-cancer analog by complexation with nicotamide. Int $J$ Pharm. 19: 17-25.

United State Pharmacopoeia. (2002), United State Pharmacopoieal Convention, 1263.

Zahran F, Gouda AA, Amin AS, El-sheikh R. (2007), Spectrophotometric determination of pipezethate $\mathrm{HCl}$, dextromethorphan $\mathrm{HBr}$ and drotaverine $\mathrm{HCl}$ in their pharmaceutical preparations. Spectrochim Acta A. Molecular and Biomolecular Spectroscopy 67(3-4): 10881093. 